\title{
DÜBLIN
}

Technological University Dublin

ARROW@TU Dublin

\section{The application of digital accelerometers for wired and non-wired Mechanomyography}

\author{
Niall Campbell \\ Technological University Dublin, niall.campbell@tudublin.ie \\ Thomas Egan \\ Technological University Dublin \\ Catherine Deegan \\ Technological University Dublin, catherine.deegan@tudublin.ie
}

Follow this and additional works at: https://arrow.tudublin.ie/engscheleart

Part of the Electrical and Computer Engineering Commons

\section{Recommended Citation}

N. Campbell, T. Egan and C. Deegan, "The application of digital accelerometers for wired and non-wired Mechanomyography," 2017 28th Irish Signals and Systems Conference (ISSC), 2017, pp. 1-6, doi: 10.1109/ ISSC.2017.7983619.

This Conference Paper is brought to you for free and open access by the School of Electrical and Electronic Engineering at ARROW@TU Dublin. It has been accepted for inclusion in Conference papers by an authorized administrator of ARROW@TU Dublin. For more information, please contact arrow.admin@tudublin.ie, aisling.coyne@tudublin.ie,gerard.connolly@tudublin.ie.

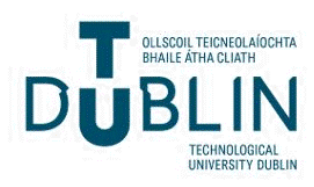




\title{
The application of digital accelerometers for wired and non-wired Mechanomyography
}

\author{
Niall Campbell, Thomas Egan, Catherine Deegan \\ Department of Engineering, \\ Institute of Technology Blanchardstown, \\ Dublin 15, Ireland. \\ Email: Niall.Campbell@itb.ie
}

\begin{abstract}
The objective of this paper is to consider the use of digital accelerometers for Mechanomyographic applications. The digital outputs of the accelerometer require the consideration of additional interfacing hardware for any commercial data acquisition systems being considered. The Arduino open-source platform is shown to meet this requirement. This platform also provides access to set the data registers on the accelerometer to output data at the resolution, speed and format required. Results show that digital accelerometers provide an accurate representation of the MMG signal.

The second objective of this work was to extend this digital platform to design a wireless MMG sensor. This has been completed using open-source components and libraries. The wireless sensor can provide an inexpensive accurate representation of the MMG response for distances in excess of 30 meters.
\end{abstract}

Keywords - Mechanomyography, MMG, accelerometer, digital accelerometer

\section{INTRODUCTION}

$\mathrm{M}$ echanomyography (MMG) involves recording and quantifying the low frequency lateral vibrations of active skeletal muscle fibres [1]. MMG is measured at the skin surface reflecting the underlying lateral oscillation of the contracting muscle. These oscillations are detectable and in certain cases they are audible. The muscle vibrations have been termed acoustic myography, phonomyography, vibromyography and accelerometry over the years, but delegates at the 1995 CIBA Symposium agreed to adopt the term 'mechanomyography' [2].

MMG has been widely investigated, with changes in the amplitude and frequency response for contracting muscle suggesting that it may reflect the global firing rate of unfused motor units (MU's) [3]. The MMG has also been found to reflect the mechanical activity of single motor units, which could lead to the identification of fibre composition type and be useful in identifying the mechanisms that underlie the process of generating force in muscle [4]. Clinically, MMG is currently used in anaesthetic monitoring [5], [6] and is being considered for prosthetic control [7], [8] however research continues into its potential as a non-invasive techniques in assessing muscle performance [3].
Ouamer et. al. [9] showed that the biceps brachii muscle resonates in the transverse direction stating that 'all points at the surface of the muscle located along a direction parallel to the longitudinal axis vibrate in phase'. This lateral movement occurs in an oscillatory manner, producing sounds with frequencies that are equal to the muscles mechanical transverse resonant frequency [10]-[12].

There is no single transducer that can be termed an $\mathrm{MMG}$ sensor. A variety of detector types have been used including microphones, laser displacement sensors and accelerometers. The accelerometer was first compared to a piezoelectric contact sensor by Watakabe et al. [13] who found that they were both adequate devices for measuring an $\mathrm{MMG}$ signal, but that that the accelerometer had the additional advantage of measuring in physical units of acceleration, $\mathrm{m} / \mathrm{s}^{2}$. A further study found a condenser microphone advantageous for dynamic muscle actions while an accelerometer provides greater bandwidth [14]. When comparing an accelerometer with a laser displacement sensor, it was demonstrated that the double integral of the accelerometer corresponded to that of the laser displacement sensor, but it was found that the accelerometer should not exceed $5 \mathrm{~g}$ in weight [15].

The accelerometer is one of the cheapest and most robust MMG sensors available. Accelerometers are commonly used in a variety of applications today, from games consoles to smartphones. One of the most popular example in MMG literature is the ADXL335 from Analog Devices, Inc., (Norwood USA). The sensitivity of the ADXL335 is given as typically $330 \mathrm{mV} / \mathrm{g}$, thus providing an output in $\mathrm{m} / \mathrm{s}^{2}$ [16]. In recent years digital accelerometers have become commercially available, the term 'digital' referring to the type of output. An analogue accelerometer outputs a continuous variable voltage proportional to the acceleration whereas its digital equivalent outputs a sampled acceleration value through either an $\mathrm{I}^{2} \mathrm{C}$ or SPI (3- or 4- wire) port.

While there are many MMG publications available where the experimental work has been carried out using analogue accelerometers, the aim of this paper was to investigate the applicability of using a digital accelerometer for measuring the MMG response. There is very little reference to digital 
accelerometers being used as MMG sensors in the literature, however there are some articles on the use of wearable biosensors incorporating MEMS accelerometers and microphones.

Digital accelerometers offer similar measurement characteristics to their analogue equivalents and the integrated circuits (IC's) normally include on-board analogue to digital conversion (ADC). The ICs are programmable, offering users a range of measurement and output options. These industry standard interfaces and its programmability provide a large degree of flexibility and adaptability when adopting digital accelerometers.

This paper demonstrates how a digital accelerometer can be employed in the capture of a muscles MMG response. In this paper both analogue and digital accelerometer types were attached alongside each other on the same muscle and the resulting responses captured. The results from both systems were processed and the suitability of the digital accelerometers for MMG measurement was assessed. In addition, MMG measurements for dynamic movement or exercise may require the use of a wireless platform. The second aim of this study was to develop a low cost wireless digital accelerometer based MMG sensor and to benchmark it against a wired analogue sensor.

With any physiological measurement the timing information and accuracy of the recorded response is important, that is the sensor must accurately reflect the amplitude response and its frequency characteristics. Therefore the objective of this study is to ensure the integrity of the signal being reproduced by the digital systems being investigated.

\section{Methodology}

All measurements were taken from from two healthy individuals (mean: age 48 yrs., mass $85 \mathrm{Kg}$, height $1.7 \mathrm{~m}$ ) with no reported musculoskeletal disorder.

The MMG response to an electrical stimulation has been reported in studies where it is recorded as an high amplitude oscillation, followed by a lower resonant frequency response [17]-[20]. The first experiment carried out in this study compares the $\mathrm{MMG}$ response of the traditional analogue accelerometer, the ADXL335, to that of its digital equivalent the ADXL345, for a $3 \mathrm{~Hz}$ electrical stimulus of the biceps brachii.

The electrical stimulation pulse delivered to the muscle was $200 \mu \mathrm{s}$ in duration ( $2 \%$ accurate) and was delivered at a preprogrammed rate of $3 \mathrm{~Hz}(2 \%$ accurate). The stimulating current was applied at $20 \mathrm{~mA}$ and the MMG response was recorded. The muscle was stimulated for 4 seconds.

The second experiment compares the MMG response of both accelerometers during an isometric contraction of the biceps brachii, a study has been widely reported [21]-[25]. After an appropriate rest period, 4 minutes, the biceps brachii was contracted to $100 \%$ maximum voluntary contraction (MVC) by bracing the forearm to a stationary object. This method allowed for no shortening of the muscle and the contraction was maintained for 4 seconds.

\section{A. Equipment}

The biceps brachii was electrically stimulated using a NeuroTrac ${ }^{\mathrm{TM}}$ Rehab from Verity Medical Ltd. The stimulation pulses were applied at $3 \mathrm{~Hz}$ with increasing current levels. The reusable self-adhesive electrodes which are rectangular and measure $50 \times 50 \mathrm{~cm}$ were placed as shown in Fig. 1 .

The analogue accelerometer the ADXL335 (Analog Devices, USA, size $18 \times 18 \mathrm{~mm}$ including mounting board) mounted on a breakout board was attached to the muscle using double sided tape. The accelerometers was attached to the mid-belly of the biceps brachii, where it is reported that the dimensional change of the muscle is greatest [26]. The combination of the accelerometer and printed circuit board is less than the recommended $5 \mathrm{~g}$ weight, so as not to attenuate the muscle vibration [15].

The ADXL335 was connected to an MP150 (Biopac Systems, Inc., USA). The accelerometer was sampled at $1 \mathrm{kHz}$ with no gain applied to the signal which was recorded in millivolts. The frequency range of the MMG signal is acknowledged to be less than $100 \mathrm{~Hz}$ and a high pass filter set at $5 \mathrm{~Hz}$ ensures that the response to bulk movement is removed [27]. Hence a bandpass filter such as a zero-lag, $4^{\text {th }}$ order Butterworth filter is applied [28].

\section{B. Digital Accelerometer}

The digital accelerometer the ADXL345 is a small, thin, low power, 3-axis MEMS accelerometer with high resolution (13bit) measurement with a range of up to $+/-16 \mathrm{~g}$. It has a digital output formatted as 16-bit two's complement and is accessible through either an SPI (3- or 4-wire) or an $\mathrm{I}^{2} \mathrm{C}$ digital interface [29].

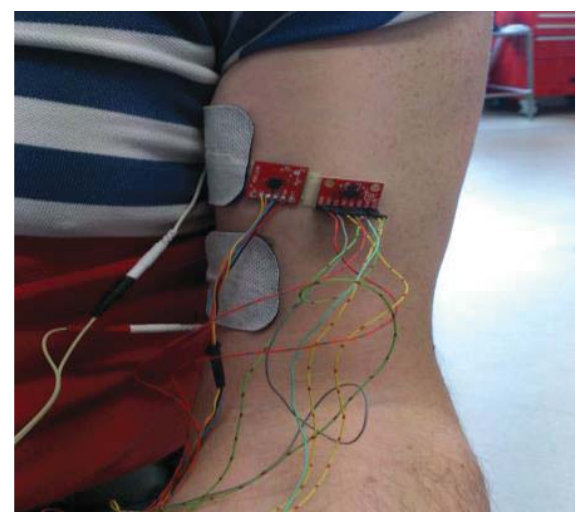

Fig. 1 Experimental Setup, position of accelerometer (ADXL335) and stimulating electrodes 
There are many data acquisition systems available on the market today that provide platforms for human studies including the MP150 from Biopac Systems, Inc. The systems design platform, Labview, from National Instruments is also popular in the literature. Both National Instruments and BioPac now provide additional hardware to connect to $\mathrm{I}^{2} \mathrm{C}$ devices, however in this study it was decided to design and test a much lower cost alternative.

The Arduino platform offers an open-source hardware and software product which can be programmed to provide an interface between the digital accelerometer and a PC, through its USB port [30]. The Arduino Uno provides an $\mathrm{I}^{2} \mathrm{C}$ serial connection to read data from the digital accelerometer [30]. The microprocessor, an ATmega328P can transmit a serial data stream through the USB port to the PC. This serial data can be read by an application running in Matlab ${ }^{\circledR}$ (Mathworks, Natick, US) or similar.

The literature quotes accelerometer sampling speeds of $1 \mathrm{KHz}$ when collecting MMG data. The range of the MMG response is between $5-100 \mathrm{~Hz}$ [31]. Using the standard factory settings the sampled data received from the accelerometer using the Arduino interface to a PC was found to be around $80 \mathrm{~Hz}$ which is too slow when sampling this response. There are two serial interfaces, the $\mathrm{I}^{2} \mathrm{C}$ interface between the Arduino and the accelerometer and the USB link between Arduino and the PC. The default output data rate (ODR) of the accelerometer is 100 $\mathrm{Hz}$, this can be increased by setting the BW_RATE register (address $0 \times 2 \mathrm{C}$ ) according to the tables (tables 7 and 8) on the datasheet [32]. To achieve the desired sampling speed it is necessary for the Arduino to continuously write a serial stream to its output, which is read directly by a data capture application. The data must also be time stamped to allow for accurate recreation of the MMG signal.

The serial data output from the Arduino board is 10 bits which provides 1024 bit levels. The system was initially tested with an analogue accelerometer, the ADXL335, which typically provides $330 \mathrm{mV} / \mathrm{g}$. The zero $g$ bias for the $x$ and $y$ axis is given as $1.5 \mathrm{~V}$ [16]. The 10-bit output represents 1024 levels between $0-5 \mathrm{~V}$ (204.8 levels/volt). To convert the input from the accelerometer to represent ' $g$ ', the following equation is applied;

$$
\text { Data }_{\text {out }}=\text { Data }_{\text {In }}-\text { Zero }_{g} / \text { scale }
$$

where, Data $_{\text {In }}$ is the data received, Zerog is the bias voltage scaled $(1.5 \mathrm{~V} \times 204.8=307.2)$ and the scale is $1 \mathrm{~g}$ scaled $(330$ $\mathrm{mV} \times 204.8=67.58)$. A test output from the accelerometer cycling from $+1 g$ to $-1 g$ is shown in Fig. 2(a).

The digital accelerometer the ADXL345 was programmed to provide a comparative accelerometer range, setting it to measure $+/-4 \mathrm{~g}$. This can be achieved by setting the two LSB's of address $0 \times 31$ according to table 20 of the datasheet [32]. The resolution at this range is 10 -bits, 1024 levels. The sensitivity
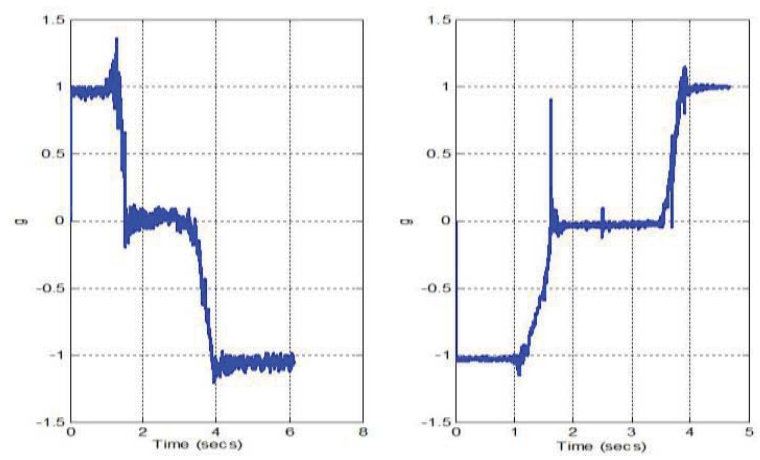

Fig. 2 Scaled accelerometer responses (ranging $+1 \mathrm{~g}$ to $-1 \mathrm{~g}$ ) from (a) ADXL335 (b) ADXL345.

at this range is typically $7.8 \mathrm{mg} / \mathrm{LSB}$. The ADXL345 output was converted to output in $g$ 's, where the scale is given in the datasheet as $128 \mathrm{LSB} / \mathrm{g}$. To scale the output the following equation is applied;

$$
\text { Data }_{\text {out }}=\text { Data }_{\text {In }} / \text { scale }
$$

where, $D_{a t a}$ is the data received, and the scale is given as 128 [32]. A comparison of both accelerometers interfaced through an Arduino and turned through the range $+/-1 \mathrm{~g}$, in the $\mathrm{x}$-axis, is shown in Fig. 2.

\section{Wireless $M M G$}

A wireless MMG sensor has been designed and tested and a block diagram of it is shown in

Fig. 3. The system is based on the Arduino platform as it provides freeware libraries for communication protocols such as $\mathrm{I}^{2} \mathrm{C}$, SPI and RF24, for use with the nRF24L01+2.4GHz wireless transceiver. This transceiver, the nRF24L01+, is widely available, has a data rate of up to $2 \mathrm{Mb} / \mathrm{s}$ and a broadcast range of around $30-50$ meters [33].

The portable sensor-transmitter unit is powered by a $3.3 \mathrm{~V}$ regulated source comprised of two CR2016 coin cell batteries. The ADXL345 is mounted on a standalone pcb with a short light wire connecting it to the transceiver using an $\mathrm{I}^{2} \mathrm{C}$ interface. This allows for flexibility in mounting the transceiver unit on the body, without adding to the mass of the sensor. The ADXL345 is continuously read by the microprocessor that in turn transmits a continuous serial stream via the radio link. The receiver board consists of a second nRF24L01+ transceiver that handles all the communications protocols, connected to an Arduino MEGA ADK.

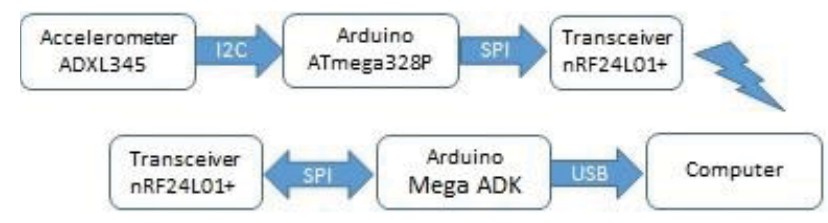

Fig. 3 Wireless MMG sensor 
This version of the Arduino has 4 serial I/O pins offering the option of separately receiving data from all three axes of the accelerometer or alternatively, all together in a single data stream. The Arduino Mega ADK decodes and outputs the accelerometer lateral axis data at a rate of $128 \mathrm{kbps}$ over a serial interface through the USB interface to the PC.

\section{RESULTS}

The initial test was conducted to evaluate the accuracy of the Arduino / ADXL335 combination in reproducing the MMG response provided by the Biopac / ADXL335 combination. Both systems simultaneously recorded the acceleration data. The resulting output was bandpass filtered at $5-100 \mathrm{~Hz}$.

\section{A. Arduino interface under test}

The initial experiment was used to compare an ADXL335 connected to MP150 BioPac with a second ADXL335 interfaced through an Arduino. The responses were comparable, with a very slight difference in amplitude in the accelerometer interfaced through the Arduino. This is perhaps as a result of different sensor mounting locations on the muscle which is known to affect the amplitude of the MMG response [39],[40].

\section{B. Digital Accelerometer}

Satisfied that the Ardino platform was capable of replicating the response of the MP150 system, the analogue accelerometer was replaced with its digital equivalent, the ADXL345.

The biceps brachii was stimulated at $3 \mathrm{~Hz}$ and simultaneous results were obtained from an ADXL335 - MP150 combination and an ADXL345 - Arduino combination. The results are shown in Fig. 4. Both signals were processed through a bandpass filter and converted to measure $g$ 's. Both systems yielded similar MMG results.

The second experiment involved a muscle being isometrically contracted to $100 \%$ MVC with the same accelerometer configurations still attached to the biceps brachii. The signal was recorded for 4 seconds and band pass filtered. An extract of the response is reproduced in Fig. 5. Again both systems provided a very similar MMG response.

In addition to the amplitude response, the frequency response of MMG is also important to researchers. A power spectral density (PSD) was performed on both the isometric responses and a comparison of the responses is shown Fig. 6. The sensors are placed side-by-side on the biceps brachii with the PSD showing a strong correlation between the two signals.

\section{Wireless platform}

The wireless version, with an ADXL345 accelerometer was placed alongside the ADXL335-MP150 combination on the biceps brachii, and subjected to the same tests as previously described.
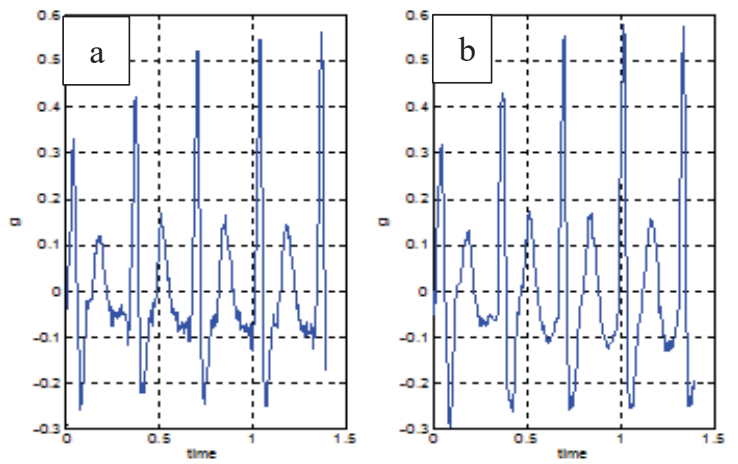

Fig. 4 Comparison of the MMG signal from an (a) ADXL335 interfaced through an MP150 and (b) ADXL345 interfaced through an Arduino, for a $3 \mathrm{~Hz}$ electrical stimulus of the biceps brachii.

Initially an electrical stimulus was applied to the muscle at $3 \mathrm{~Hz}$ and this was followed by an isometric contraction of the muscle at $100 \%$ MVC. The first test, a $3 \mathrm{~Hz}$ electrical stimulation and the response from both sensors is shown in Fig. 7(a). There is also evidence of a strong correlation, Fig. 7(b). Slight difference may be accounted for by acceleroemeter placing on the limb.

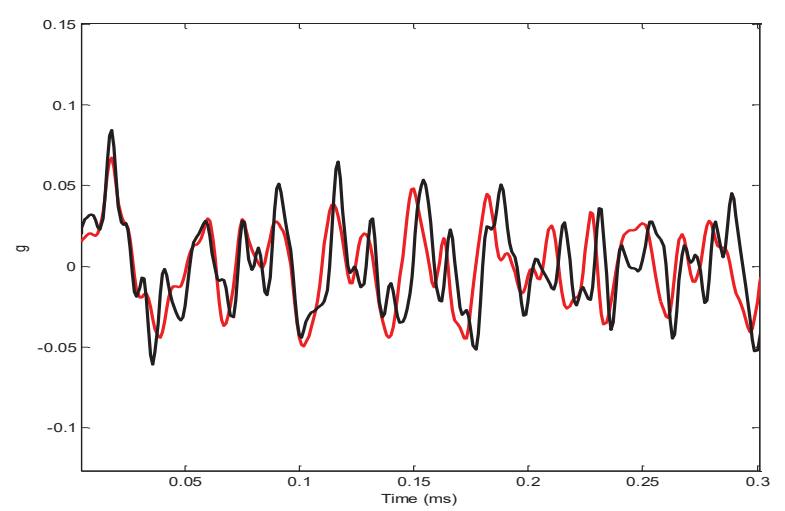

Fig. 5 MMG response from an (a) ADXL335 interfaced through an MP150 (black) and (b) ADXL345 interfaced through an Arduino (red) for an isometric contraction of the biceps brachii at 100\% MVC

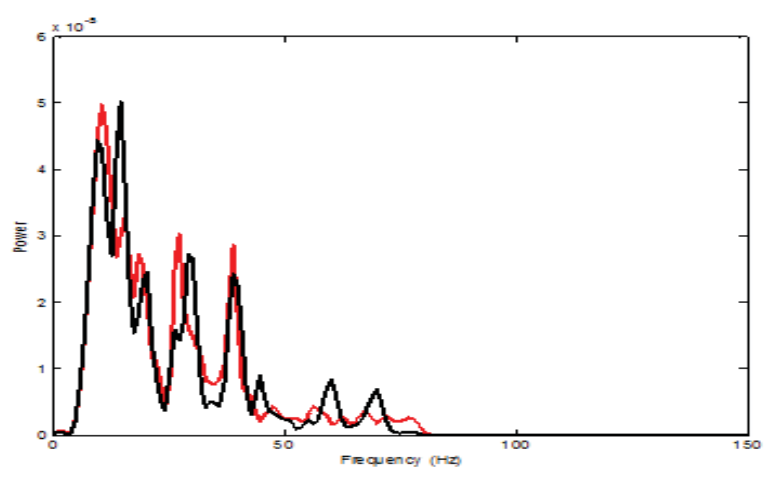

Fig. 6 PSD of the MMG response from an (a) ADXL335 interfaced through an MP150 (black) and (b) ADXL345 interfaced through an Arduino (red) for an isometric contraction of the biceps brachii at $100 \%$ MVC 

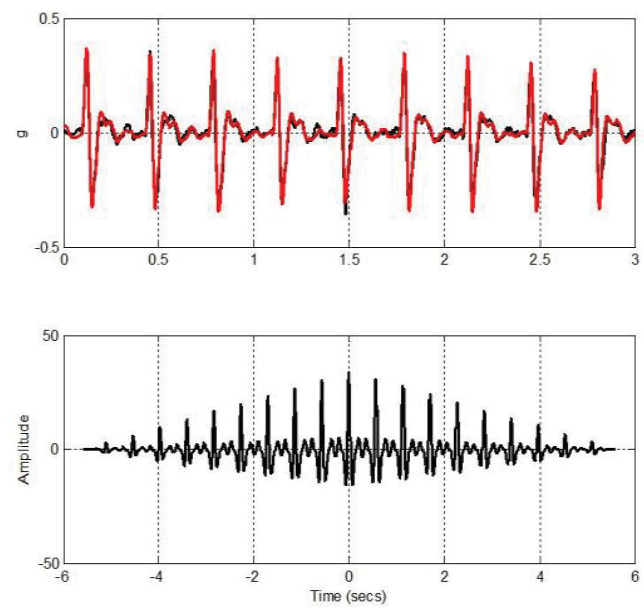

Fig. 7 Electrical Stimulus MMG response at $3 \mathrm{~Hz}$ (top) Biopac - ADXL335 combination (red) and the wireless Arduino - ADXL345 combination (black) and (bottom) cross-correlation of the two MMG responses

The MMG from both systems was then used to capture a maximum isometric contraction of the biceps brachii. Reported results were reproduced by the frequency analysis, Fig. 8, peaking around $12 \mathrm{~Hz}$, and with a time-frequency response, showing maximum intensity above wavelet $2(11.31 \mathrm{~Hz})[18]$, [31].

\section{CONCLUSION}

This paper looked to investigate the suitability of using a digital accelerometer to capture the MMG response from a muscle. There are some wireless MMG sensors available from vendors, that use MEMS microphones [36], and others that aim to use body sensors attached to clothing for stroke rehabilitation [37], however at this time there are no reports published regarding the use of digital accelerometers in MMG applications. The Arduino was considered as a low cost interface as it offers an open-source platform with all the required libraries. All the tests conducted demonstrate that the digital accelerometer and the Arduino based interfaces are capable of producing a reliable, reproducible $\mathrm{MMG}$ response.

The equivalent digital accelerometer, the ADXL345, was compared to the analogue version, albeit with a greater range $(+/-4 g)$. It is necessary for the digital platforms to timestamp the data received so that the recovered response can be accurately reproduced.

The MMG response from two experiments, first for an electrical stimulus and then for an isometric contraction are shown in Fig. 4 and Fig. 5. The frequency response of the MMG is also of interest, therefore a PSD was produced for both responses with both demonstrating a similar frequency response, Fig. 6.

Many of today's athletes and even 'fun' runners are collating GPS and biological data such as the heart rate. In cycling ergometry the MMG amplitude has also been found to increase
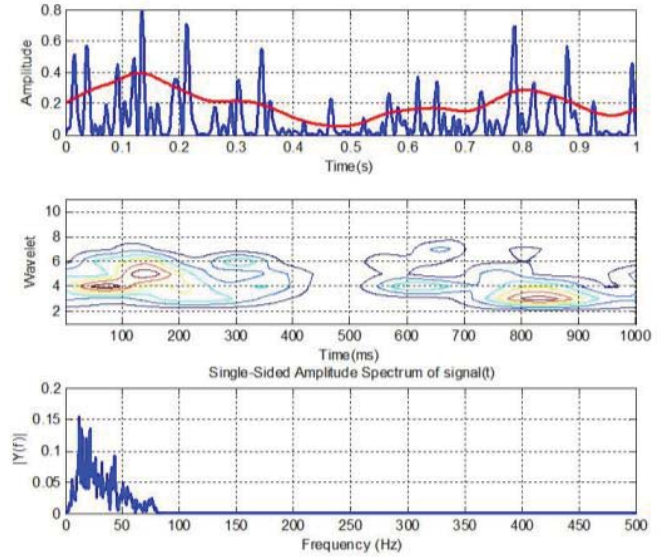

Fig. 8 Total intensity (top), time-frequency analysis (middle) and FFT (bottom) of the MMG response for a maximum isometric contraction of biceps brachii captured with wireless digital MMG system

with increasing power output [37]-[39]. In applications such as for dynamic activities a wireless MMG data capture platform may be useful. A low cost wireless MMG sensor was designed and both experiments again applied to this platform. The resulting response from this wireless system reproduced responses closely correlated to those from the analogue wired version, Fig. 7 and reproducing an expected frequency response, Fig. 8.

In conclusion, a digital accelerometer is capable of accurately measuring the MMG response. The main difference in using a digital accelerometer is that unlike its analogue counterpart which provides a direct analogue output, it offers both an $\mathrm{I}^{2} \mathrm{C}$ and SPI digital interface. These interfaces are not directly available to connect to a PC or a data acquisition system, therefore additional hardware is required to sample the digital accelerometer and provide an interface. A low cost interface has been suggested here based on the Arduino platform. This interface has been tested and has yielded MMG responses that replicate the analogue system.

The digital accelerometer platform can be expanded to provide for a wireless MMG sensor. This wireless sensor provides a range of over $30 \mathrm{~m}$, and it has been demonstrated that is also yielded a reliable MMG response. This wireless platform is open-source, so provides a flexible and low-cost sensing system for MMG in comparison to those available commercially.

The digital accelerometer has been tested for both an electrically stimulated and for an isometric contraction response. This study has shown that digital accelerometers offer a viable alternative to the analogue versions for $\mathrm{MMG}$ measurement.

\section{REFERENCES}

T. W. Beck, T. J. Housh, J. T. Cramer, J. P. Weir, G. O. Johnson, J. W. Coburn, M. H. Malek, and M. Mielke, "Mechanomyographic amplitude and frequency responses during dynamic muscle actions: a comprehensive review.," Biomed. Eng. Online, vol. 4, no. 1, p. 67, Jan. 2005. 

in muscle studies," Crit. Rev. Biomed. Eng., vol. 21(3), pp. 201-243, 1993.

[3] M. O. Ibitoye, N. A. Hamzaid, J. M. Zuniga, and N. Hasnan, "Mechanomyographic Parameter Extraction Methods: An Appraisal for Clinical Applications," Sensors, vol. 14, pp. 22940-22970, 2014.

[4] T. W. Beck, "The mechanisms underlying the surface mechanomyogram," in Applications of Mechanomyography for examining muscle function, Travis W B., vol. 661, no. 2, T. W. Beck, Ed. Kerala, India: Transworld Research Network, 2010, pp. 1-16.

[5] T. M. Hemmerling, G. Michaud, D. Babin, G. Trager, and F. Donati, "Comparison of phonomyography with balloon pressure mechanomyography to measure contractile force at the corrugator supercilii muscle.," 2004.

[6] C. Claudius, L. T. Skovgaard, and J. Viby-Mogensen, "Acceleromyography and mechanomyography for establishing potency of neuromuscular blocking agents: a randomized-controlled trial.," Acta Anaesthesiol. Scand., vol. 53, no. 4, pp. 449-54, Apr. 2009.

[7] D. T. Barry, J. J. Leonard, A. Gitter, and R. Ball, "Acoustic myography as a control signal for an externally powered prosthesis.," Arch Phys Med Rehabil., vol. 67(4), pp. 267-9, 1986.

[8] H.-B. Xie, Y.-P. Zheng, and J.-Y. Guo, "Classification of the mechanomyogram signal using a wavelet packet transform and singular value decomposition for multifunction prosthesis control.," Physiol. Meas., vol. 30, no. 5, pp. 441-57, May 2009.

[9] M. Ouamer, M. Boiteux, M. Petitjean, L. Travens, and A. Salès, "Acoustic myography during voluntary isometric contraction reveals non-propagative lateral vibration.," J. Biomech., vol. 32, pp. 1279 $1285,1999$.

[10] D. T. Barry and N. M. Cole, "FLUID MECHANICS OF MUSCLE VIBRATIONS,” Biophys. J., vol. 53, no. June, pp. 899-905, 1988.

[11] D. T. Barry and N. M. Cole, "Muscle sounds are emitted at the resonant frequencies of skeletal muscle.," IEEE Trans. Biomed. Eng., vol. 37, no. 5, pp. 525-31, May 1990.

[12] L. E. Dobrunz, D. G. Pelletier, and T. a McMahon, "Muscle stiffness measured under conditions simulating natural sound production.," Biophys. J., vol. 58, no. August, pp. 557-565, 1990.

[13] M. Watakabe, Y. Itoh, K. Mita, and K. Akataki, "Technical aspects of mechnomyography recording with piezoelectric contact sensor.," Med. Biol. Eng. Comput., vol. 36, pp. 557-561, 1998.

[14] M. Watakabe, K. Mita, K. Akataki, and Y. Itoh, "Mechanical behaviour of condenser microphone in mechanomyography.," Med. Biol. Eng. Comput., vol. 39, pp. 195-201, 2001.

[15] M. Watakabe, K. Mita, K. Akataki, and K. Ito, "Reliability of the mechanomyogram detected with an accelerometer during voluntary contractions.," Med. Biol. Eng. Comput., vol. 41, pp. 198-202, 2003.

[16] "ADXL335 datasheet," Analog Devices, 2009. [Online]. Available: http://www.analog.com/en/products/mems/memsaccelerometers/adx1335.html. [Accessed: 10-Feb-2016].

[17] K. Akataki, K. Mita, K. Itoh, N. Suzuki, and M. Watakabe, "Acoustic and electrical activities during voluntary isometric contraction of biceps brachii muscles in patients with spastic cerebral palsy.," Muscle nerve, vol. 20, pp. 764-765, 1997.

[18] T. W. Beck, T. J. Housh, G. O. Johnson, J. T. Cramer, J. P. Weir, J. W. Coburn, and M. H. Malek, "Does the frequency content of the surface mechanomyographic signal reflect motor unit firing rates? A brief review.," J. Electromyogr. Kinesiol., vol. 17, no. 1, pp. 1-13, Feb. 2007.

[19] C. Orizio, F. Esposito, E. Alfonsi, and F. Umana, "Surface mechanomyogram reflects the changes in the mechanical properties of muscle at fatigue," pp. 276-284, 1999.

[20] Y. Yoshitake, M. Shinohara, H. Ue, and T. Moritani, "Characteristics of surface mechanomyogram are dependent on development of fusion of motor units in humans.," J. Appl. Physiol., vol. 93, no. 5, pp. 1744 52, Nov. 2002.

[21] T. W. Beck, T. J. Housh, G. O. Johnson, J. P. Weir, J. T. Cramer, J. W. Coburn, and M. H. Malek, "Comparison of a piezoelectric contact sensor and an accelerometer for examining mechanomyographic amplitude and mean power frequency versus torque relationships during isokinetic and isometric muscle actions of the biceps brachii," J. Electromyogr. Kinesiol., vol. 16, no. 4, pp. 324-335, Aug. 2006.
[22] C. Cescon, E. Sguazzi, R. Merletti, and D. Farina, "Non-invasive characterization of single motor unit electromyographic and mechanomyographic activities in the biceps brachii muscle.," $J$ Electromyogr. Kinesiol., vol. 16, pp. 17-24, 2006.

[23] T. Kimura, T. Hamada, T. Watanabe, A. Maeda, T. Oya, and T. Moritani, "Mechanomyographic responses in human biceps brachii and soleus during sustained isometric contraction.," 2004.

[24] A. Jaskólska, P. Madeleine, A. Jaskólski, K. Kisiel-Sajewicz, and L. Arendt-Nielsen, "A comparison between mechanomyographic condenser microphone and accelerometer measurements during submaximal isometric, concentric and eccentric contractions.," $J$. Electromyogr. Kinesiol., vol. 17, pp. 336-347, 2007.

[25] C. Orizio, M. Gobbo, B. Diemont, F. Esposito, and A. Veicsteinas, "The surface mechanomyogram as a tool to describe the influence of fatigue on biceps brachii motor unit activation strategy. Historical basis and novel evidence.," Eur. J. Appl. Physiol., vol. 90, pp. 326336, 2003.

[26] Y. Yoshitake, K. Masani, and M. Shinohara, "Laser-detected lateral muscle displacement is correlated with force fluctuations during voluntary contractions in humans.," J. Neurosci. Methods, vol. 173 no. 2 , pp. 271-8, Aug. 2008.

[27] T. W. Beck, "Technical aspects of surface mechanomyography," in Applications of Mechanomyography for examining muscle function, vol. 661, no. 2, T. W. Beck, Ed. Transworld Research Network, 2010 , pp. 95-107.

[28] T. W. Beck and V. von Tscharner, "Concentric and eccentric isokinetic muscle activity separated by paired pattern classification of wavelet transformed mechanomyograms," Biomed. Signal Process. Control, vol. 4, no. 2, pp. 94-101, Apr. 2009.

[29] "Sparkfun Triple Axis Accelerometer Breakout - ADXL345." [Online]. Available: https://www.sparkfun.com/products/9836. [Accessed: 09-Mar-2016]

[30] “Arduino." [Online]. Available: https://www.arduino.cc/. [Accessed: 09-Mar-2016].

[31] T. W. Beck, V. Von Tscharner, T. J. Housh, J. Cramer, J. Weir, M. Malek, and M. Mielke, "Time/frequency events of surface mechanomyographic signals resolved by nonlinearly scaled wavelets," Biomed. Signal Process. Control, vol. 3, no. 3, pp. 255 266, Jul. 2008.

[32] “ADXL345 - datasheet," Analog Devices, 2011. [Online]. Available: http://www.analog.com/media/en/technical-documentation/datasheets/ADXL345.pdf. [Accessed: 08-Feb-2016]

[33] D. a. Engelien-Lopes, "Benefits of total integration for large RF circuits, market requirements in terms of cost and current and commercial standards vs. optimum solutions," IEE Semin. Telem. Telemat., vol. 2005, pp. 9-9, 2005

[34] C. Cescon, P. Madeleine, T. Graven-Nielsen, R. Merletti, and D. Farina, "Two-dimensional spatial distribution of surface mechanomyographical response to single motor unit activity.," $J$. Neurosci. Methods, vol. 159, no. 1, pp. 19-25, Jan. 2007.

[35] D. Farina, X. Li, and P. Madeleine, "Motor unit acceleration maps and interference mechanomyographic distribution.," J. Biomech., vol. 41, no. 13 , pp. 2843-9, Sep. 2008

[36] "LPEMMG-B - EMG / MMG Sensor with Bluetooth (Wireless) Connectivity." [Online]. Available: http://www.lpresearch.com/lpemmg-b-electromyography-mechanomyogramsensor-solution-with-bluetooth-connectivity/. [Accessed: 18-May2006].

[37] J. Burridge, "New wireless sleeve to help people recover arm use after stroke," $2016 . \quad$ [Online]. Available: http://www.southampton.ac.uk/news/2016/01/m-mark.page. [Accessed: 18-May-2016].

[38] S. R. Perry, T. J. Housh, G. O. Johnson, K. T. Ebersole, A. J. Bull, T. K. Evetovich, and D. B. Smith, "Mechanomyography, electromyography, heart rate, and ratings of perceived exertion during incremental cycle ergometry.," J. Sports Med. Phys. Fitness, vol. 41, pp. 183-188, 2001.

[39] J. R. Stout, T. J. Housh, G. O. Johnson, T. K. Evetovich, and D. B. Smith, "Mechanomyography and oxygen consumption during incremental cycle ergometry," Eur. J. Appl. Physiol. Occup. Physiol., vol. 76, no. 4, pp. 363-367, 1997. 